\title{
Contextual factors that shape recovery after stroke in Malaysia
}

\section{Fatima Fanna Mairami, Narelle Warren, Pascale A. Allotey \& Daniel D. Reidpath}

To cite this article: Fatima Fanna Mairami, Narelle Warren, Pascale A. Allotey \& Daniel D. Reidpath (2019): Contextual factors that shape recovery after stroke in Malaysia, Disability and Rehabilitation, DOI: 10.1080/09638288.2019.1588399

To link to this article: https://doi.org/10.1080/09638288.2019.1588399

\section{册 Published online: 05 Apr 2019.}

Submit your article to this journal $₫$

Џ Article views: 46

View Crossmark data \lceil 


\title{
Contextual factors that shape recovery after stroke in Malaysia
}

\author{
Fatima Fanna Mairami ${ }^{\mathrm{a}}$ (D), Narelle Warren ${ }^{\mathrm{b}}$ (D), Pascale A. Allotey ${ }^{\mathrm{c}}$ (D) and Daniel D. Reidpath ${ }^{\mathrm{a}, \mathrm{d}}$ \\ a Jeffrey Cheah School of Medicine and Health Sciences, Monash University Malaysia, Bandar Sunway, Malaysia; ${ }^{b}$ School of Social Sciences, \\ Monash University, Clayton Campus, Melbourne, Australia; ${ }^{C}$ UN University International Institute for Global Health (UNU-IIGH), Kuala Lumpur, \\ Malaysia; ${ }^{d}$ South East Asia Community Observatory (SEACO), Monash University, Segamat, Malaysia
}

\section{ABSTRACT}

Purpose: A stroke is a sudden event which may leave individuals and their families ill-prepared to deal with the resultant disability. Several contextual factors can influence the recovery process. These factors, internal and external, exist interactively in the lived experiences of the survivors. The limited availability of rehabilitation centres that are located in urban centres meant that recovery predominately occurred outside of the biomedical health and instead relied upon the resources available to individuals and their families.

Methods: A qualitative approach with data from in-depth interviews and observations were used to identify contextual factors that shaped recovery following stroke in a community. Twenty-seven individuals with stroke were drawn from a health and demographic surveillance system in Malaysia.

Results: Hope and optimism, coping strategies, motivation and support from family and friends, and the use of alternative and complementary medicine shaped the process of recovery within a context where infrastructure is extremely limited.

Conclusion: The identification of factors that facilitate the recovery process provides a background in which health care providers can utilise to improve their understanding of the stroke experience. Such understanding could be instrumental in aiding health professionals to offer the most effective help to their clients.
> IMPLICATIONS FOR REHABILITATION

- Identification of contextual factors provides a background for the understanding of the stroke experience.

- Incorporation of religion into rehabilitation could support and maintain hope in recovery for the survivors and aid acceptance.

- A collaboration of healthcare professionals with traditional medicine therapists may prove beneficial for the rehabilitation of stroke survivors in Malaysia.

\section{ARTICLE HISTORY}

Received 4 July 2018

Revised 24 February 2019

Accepted 25 February 2019

\section{KEYWORDS}

Stroke; recovery; hope and optimism; coping strategies; family support;

complementary and

alternative medicine

\section{Introduction}

A stroke is a sudden event which may leave individuals and their families ill-prepared to deal with the resultant impairments $[1,2]$. Stroke is associated with physical, emotional and social consequences that affect an individual's quality of life [3-5]. Individuals with stroke aim to return to active living and reintegrate into society [6]. The conventional approach to stroke recovery is the delivery of rehabilitation services based on the medical principles of cure [7-9]. Clinical measures of recovery following stroke alone fail to offer a complete picture of what constitutes a successful recovery $[10,11]$. Accordingly, some studies have suggested that stroke survivors measured the impact of the condition about the emotional and social domains of their lives [10].

Although stroke recovery may be individualised, multiple factors influence a person's progress - recovery - following a stroke. These may include internal factors (such as optimism, fears of dependency, or personal control), external factors (such as therapeutic interactions), or a combination of these, and which can hinder or facilitate recovery [11]. Prior studies have highlighted the despair and disappointment felt by stroke survivors after discharge from the hospital due to limited information given and encouragement by health professionals [12-15]. Other studies have found that individuals developed and used a range of coping strategies to adjust to life with stroke $[16,17]$.

While these findings have investigated the factors that augment or undermine the process of recovery for individuals with stroke internationally, few studies have discussed the contextual factors involved in stroke recovery in Malaysia [18]. An understanding of these elements that influence recovery following a stroke could be instrumental in aiding health professionals to offer the most effective help to their clients.

A rehabilitative approach to post-stroke care may pose challenges to Malaysian stroke survivors given the limited availability and accessibility of specialised stroke care in Malaysia [19]. The inadequacy of such services could impact on recovery, making evident a need to focus on contextual dimensions of recovery. Of course, one of the challenges in Malaysia is that such recovery needs to be self-directed or using local health services, given the lack of rehabilitation facilities in the country, and particularly in rural areas. The development of such services, however, must 
consider the experience of recovery from the perspective of the stroke survivor $[7,20]$ as the views of people with disabilities are required to fully understand what is of value to them and develop interventions that are tailored to their needs [21].

In this paper, we aim to explore the contextual factors that mediate recovery following stroke in Malaysia, a middle-income country, from the perspective of stroke survivors. In examining individual narratives of recovery collected from 27 rural Malaysians, we seek to elucidate the personal, social and community-level elements influencing the recovery process.

\section{Methods}

\section{Participants}

This study was part of a larger ethnographic study that explored the experience of stroke in Malaysia at a health and demographic surveillance system (HDSS), the South East Asia Community Observatory (SEACO), located in rural Peninsular Malaysia. The platform, SEACO, operates across five sub-districts, and yearly census rounds are conducted to collect information on an extensive range of health conditions among the enrolled population [22]. People were included in the study if they had ever experienced a stroke, could communicate personally or with the aid of a caregiver, and could, therefore, provide informed consent for participation. Participant recruitment proceeded as follows: the household census included four self-report questions based on the WHO's F.A.S.T (face, arms, speech and time) criteria. Where an affirmative response was recorded for at least two of these four items, individuals were identified as having potentially experienced stroke. These individuals were then visited by the research team to confirm whether they had experienced stroke. To do this, Author A, a medical doctor, drew upon her clinical expertise to evaluate the individual's health history and any presence of signs/ symptoms. Of the 64 individuals initially identified, 21 did not suffer a stroke, ten were uncontactable despite several visits to their homes, five refused consent, three were too ill to participate in the study, and one passed away before consent was obtained. Twenty-four individuals consented to participate. A further three individuals were identified via the HDSS community liaisons personnel; all were confirmed to have suffered a stroke and consented to participate. The final study sample consisted of 27 participants, including 21 men and six women. While this gender difference reflected trends recorded in the HDSS data indicating more men had experienced stroke, it contrasted with epidemiological data in Malaysia highlighting that while men do experience more stroke than women, the gender difference is more moderate [23].

\section{Procedure}

Semi-structured interviews with the first author and an interpreter were conducted to explore the barriers and facilitators to stroke recovery. All interviews took place in the participants' homes and lasted from 30 minutes to 2 hours per session over 2-3 research encounters. Data from the interviews were supplemented by extensive field-notes taken to document participants' non-verbal responses and the surrounding environment. To reduce recall bias, specific questions about the stroke event were asked. These responses were then explored in greater detail during subsequent research encounters to corroborate the information provided and add to study rigour. Caregivers (spouses, children, and siblings) were present during the interviews. The caregivers participated by augmenting and clarifying information provided by the stroke survivor. All interviews were audio-recorded with permission from participants, translated, and then transcribed verbatim. Discussions with the stroke survivors focused on how their experience of stroke evolved, how they coped and reconstructed themselves.

Furthermore, we explored their views about the health care they received, were receiving at the time of study participation, and how conventional and traditional interventions if any, facilitated or hindered their recovery. Broad questions were asked during the interviews (see Table 1 for the interview guide synopsis).

\section{Data analysis}

As analysis commenced, relevant themes were identified and recorded in a separate worksheet that was later used to explore the linkages between themes. Initially, this contained general insights and was modified as the study advanced. The process was subjective and reflective, consistent with ethnographic research [24]. Essential themes were identified and reported. Gaps and missing data were identified during the analysis and followed up as fieldwork progressed. Analysis commenced following the first encounter with participants and continued throughout the study. A six-stage thematic analysis technique was used [25]. The data set, interview transcripts and field-notes were compared against each other to ensure validity and reliability. The transcripts and field-notes were read in their entirety the first time to provide familiarity with the content. The second reading resulted in a line-by-line analysis to extract initial codes. Following initial coding, the codes were categorised into potential themes. The themes were then sorted into groups and cross-checked against the transcripts and field-notes to ensure consistency with the research question. The themes were then modified accordingly, and quotes from the participants used to exemplify them.

\section{Ethics}

The study was approved by Monash University Human Research Ethics Committee (CF14/315-2014000105). The researcher provided detailed verbal information about the aims and objectives of the study, what participation involved, and any implications of participation. This was also provided as a hard-copy plain language information statement. Informed consent was obtained verbally at the time of recruitment into the study and again before each encounter; as potential participants were reluctant to sign documents; verbal informed consent was sought. Participants with communication difficulties or memory problems provided assent to participate, and their caregivers provided formal consent. All names used in this paper are pseudonyms.

Table 1. Interview guide.

Can you tell me about the day your stroke occurred? What were you doing? What do you think caused the stroke? What happened next? Where did you go? Tell me what happened at the hospital/clinic What did the doctors say caused the stroke?

Before you left the hospital, what did the doctor tell you?

Did you go to any other place for treatment? What other treatment did you seek? Who else treated you?

Can you tell me about your daily routine?

How has life changed since the stroke?

How did you manage your life after the stroke?

Did you seek any help? Who helped you?

How did your faith help? Did the stroke affect your religious practices? Is there anything else you would like to tell or ask me? 


\section{Findings}

Participants ranged in age from 37 to 83 years (Table 2). Twenty participants were of Malay ethnicity, four were Indian, and three were Chinese. Considerable variation was found in the time since stroke, ranging from 3 weeks to 32 years. This allowed examination of the experience of stroke across the spectrum of recovery, which is the central concern of the current paper. All participants lived with one or more family members, and all reported receiving informal support from family, friends, community members, or traditional therapists (including traditional Malay healers or Chinese Medical Practitioners). Caregivers were most commonly spouses of the stroke survivors $(n=25)$.

All participants experienced some residual impairment from the stroke, including weakness or paralysis on one side of the body and slurred speech. Five participants had communication difficulties, and two others had trouble with attention. For these participants, interviews were augmented through the use of (C)Talking Mats, a communication device that uses picture symbols to assist individuals with (or without) communication difficulty to comprehend and respond to questions [26]. The (C)Talking Mats also helped in sustaining their attention by giving them time to reflect on the questions asked and respond at their own pace [27]. A few used assistive devices, such as a cane, tripod or, a wheelchair. One participant moved about permanently on a wheelchair, and another was completely immobile and confined to a bed. The participants often had other health problems, including diabetes, hypertension, asthma, and gout. Time since the stroke and the number of strokes experienced undoubtedly affected participants' recovery experiences; however, as there was no clear pattern of how these variables affected people's recovery.

The participants' narratives identified several factors that facilitated or hindered their recovery experience and included internal or external mediators. Internal mediators included hope and optimism, self-efficacy and self-motivation, coping strategies, and comorbidities. External mediators included family and social support, access to or the presence of empowered health professionals, and treatment management strategies.

Table 2. Characteristics of study participants.

\begin{tabular}{lc}
\hline Variable & Frequency (\%) \\
\hline Gender & F: $6(22.2)$ \\
Age (years, at time of first interview) & M: $21(77.8)$ \\
& $30-39: 1(3.7)$ \\
$40-49: 3(11.1)$ \\
$50-59: 8(29.6)$ \\
$60-69: 9(33.3)$ \\
$70+: 6(22.2)$
\end{tabular}

Ethnicity

Chinese: $3(11.1)$

Indian: 4 (14.8)

Malay: 20 (74.1)

Religion

Islam: 20 (74.1)

Christianity: 1 (3.7)

Buddhism: 2 (7.4)

Hinduism: 3 (11.1)

None declared: 1 (3.7)

Years of stroke (at time of recruitment)

<: $12(44.4)$

4-10: 9 (33.3)

$10+: 6(22.2)$

Single: $1(3.7)$

Married: 25 (92.6)

Widowed: 1 (3.7)

Primary caregiver

Spouse: 25 (92.6)

Daughter in law: 1 (3.7)

None: 1 (3.7)

\section{Internal mediators}

\section{Hope and optimism}

The recovery path was often paved with frustrations and challenges and, as such, hope allowed individuals to have a positive mindset towards recovery. Whether hope originated from within the individual or from those around them, it fostered optimism for a functional and meaningful life. Ayub, aged 48 years (5 yearspost-stroke), pointed out that learning about the positive outcomes of other stroke survivors provided him with hope:

I once went for a massage [and] I could sit on the chair. Another person came. His family carried him. He was just lying down. He had it, I had it, [we] both had a stroke. In two months, he recovered, just like a normal person. No imbalanced gait. But I am still imbalanced. I asked him, "Uncle what did you do?" He said once he recovered a bit, he exercised. I can't even grip ... no strength right, that's why I can't. But I think we use this (points to the head), every day we use the mind. As time goes by, if we try harder ... we can recover.

Ayub's statement offered insights into the relationship between hope and recovery. Observing the progress of an individual with severe stroke made had him realise that if he worked towards recovery, he would recover. Seeing others' positive outcomes reinforced participants' beliefs that recovery could happen.

However, not all participants had hope in recovery. As the rate of improvement was wide-ranging among participants, some lost hope in recovery when their progress was slow. Hanif, aged 74 years (4 years-post-stroke), viewed his recovery as an impossibility:

Hope? There's no more. Usually, people who got this [stroke] recovered by the $4^{\text {th }}$ or $5^{\text {th }}$ month. Me, three years but still the same. This is getting tougher, can't even get up, legs are stiff.

Hanif, who had previously attended massage sessions and practised standing and walking by supporting himself against the wall now hardly performed any exercises. He spent much of his time sitting on the floor in his home, with most of his social contact occurring when visitors would come. Hanif was no longer able to attend mosque or community events. His lack of optimism about recovery meant he rarely partook in processes of recovery. He seemed depressed and mentioned a complete absence of happiness in his life - which impacted his capacity to participate in recovery-directed activities actively.

\section{Self-efficacy and self-motivation}

Self-efficacy is the ability to organise and execute the courses of action that are required for attaining certain goals and was defined as a person's confidence in their ability to perform a task [28]. In shaping the course of action to take, the amount of effort to put in, and a person's determination to carry on despite obstacles, self-efficacy beliefs played a central role in stroke recovery. Participants had confidence in their ability to steer their recovery. When Ayub's stroke affected his right hand and arm, he learned to write with the left:

This hand, (shows left hand) writes. I used to write with the right. Now I use this hand to write. Learn, learn until I could write... but all in large letters.

Ayub's successful performance of writing boosted his confidence and encouraged him to perform more complex tasks such as driving. Similarly, the participants reflected on feelings of helplessness and dependency on others that triggered a change in attitude and led to their progress toward independent 
functioning. This desire to be independent motivated them to work towards achieving recovery:

I laid here...for nearly three months. I couldn't walk. My wife massaged me, took care of me, fed me. I couldn't get up. After that I thought to myself, you can't be like this. I must fight back. Then I got up and started moving. I walked to the mosque. Early in the morning, I started going around, walk, and walk! (Shuaib, aged 68 years, 11years post-stroke)

Shuaib, like most other stroke survivors and in contrast to Hanif, refused to passively accept the changes caused by his stroke and sought to find self-management activities which enhanced functionality and independence. These participants had higher levels of self-efficacy and focused on exercising and relearning skills to overcome the challenges of their disability. Umar, aged 56, (5 years-post-stroke) for example, believed exercises would aid in his recovery. Despite not having access to planned health professional rehabilitation (like most of the participants in our study), he performed strengthening exercises: "I do exercises on my own. I just walk around, ride the bicycle. Then when I do prayers [salah], that is also some exercise." For Umar, the physical activity involved in the salah, which comprises a series of postural movements and involve all the muscles and joints of the body, served as a form of exercise.

These participants recognised that their attitudes of determination, self-motivation and pushing limits were a significant facilitator to their recovery.

\section{Coping Strategies}

The participants were compelled to find ways to cope with the challenges brought about by the stroke. As they learned more about their body and its limitations, participants developed a wide range of strategies, which included turning to religion, active coping, and performing activities at a slower pace.

In this study, the majority of the participants turned to religion to help them cope effectively with their condition. They used their faith to seek strength and deal with the challenges posed by the stroke. For the Muslim participants, the stroke was viewed as a test from God. Accepting the stroke and its consequences, therefore, meant believing in God's supremacy. Razak, aged 76 years, said during the interview, "If God wants us to have a stroke until death, then so be it. We accept it." Shuaib, a deeply religious man, emphasised, "If Allah wants us to recover, we definitely will recover." This acceptance of the infinite power of God reduced their psychological distress as they surrendered their recovery to God. Reciting the Holy Qur'an was also vital for these participants. Yaqub's caregiver - his wife - talked about how her husband would read the Quran in the evenings since the stroke. Yaqub, a 66-year-old man at two-years post-stroke, added: "In Sha Allah, (by God's will) it can help remove, forget all the negative thoughts."

Religion for the Muslim participants supported recovery in two ways. It provided a psychological coping strategy, enabling them to accept the condition and alleviated their fears about recovery as they believed recovery would only come from God. It also provided physical ways of coping for the participants. The physical aspect of the salah, which is a fundamental requirement for all Muslims, was considered a form of exercise as Umar mentioned above.

Dram, a 47-year-old, who was not very religious before his stroke discussed how turning to his faith provided him with solace and hope in recovery. A Buddhist, he had his family take him to the temple regularly where he would pray and make sacrifices.
He prayed for strength and patience and believed his sacrifices would leverage the provision of recovery from God.

'Active coping' refers to the process of taking steps to eliminate or avoid a stressor or to ameliorate its effects [29]. Our participants tried to lessen the effects of the stroke by focusing their efforts on activities that would aid their recovery. Most participants took up or continued with past household chores at home to assist with functional motor recovery. Musa, aged 68 years (4 years-post-stroke), described his daily activity this way:

I exercise; I sweep the veranda, pick up the leaves that fall from the trees. It is like killing two birds with one stone, cleaning and exercise. Helps me a lot.

For Musa and others, their household chores were a form of exercise that was performed persistently as they believed it would help with recovery. This belief stemmed from advice given to them by health professionals, traditional therapists, and other individuals who have suffered a stroke. Household chores, although not a structured rehabilitation approach, helped the participants with muscular flexibility, strength and endurance.

Pacing activities and relaxation were other strategies employed for engaging in everyday tasks. The participants had come to accept that it was difficult to compensate for lost functions and that energy and strength were needed to keep up with living. Because of this, some of the participants chose to limit their daily activities and take regular breaks. Yaqub, for example, cut down his hours working at his rubber farm so he could have more time at home to rest. Similarly, pacing meant that they had not given up on activities they used to perform. Instead, they adjusted how they performed those activities. For the participants, this was a vital element, and it gave them a sense of normality in the face of their disability. Relaxation offered the participants relief from the stress brought about by their disabilities. Musa, who lived in a house atop a hill, would sit out in the compound overlooking the beautiful landscape:

I love to sit outside. Every morning when they [children and grandchildren] leave, I will sit there. It is quiet and nice, and the air is fresh. It makes me calm.

Relaxation has been documented in past literature as a way of providing improved concentration, confidence, motivation and improved functioning in individuals with stroke [30]. Similarly, relaxation helped to reduce stress and anxiety [30,31]. By working in pauses and scheduling in time for breaks and relaxation, participants had the vigour and strength to complete household chores, move about and generally feel good about themselves. The use of these strategies assisted the participants in accommodating their impairments and limitations by constructing new meanings to their situation, prioritising certain activities and revising values that would aid in their recovery.

\section{Comorbidities}

Many participants had pre-existing medical conditions which affected their stroke recovery. High blood pressure, diabetes, and high blood cholesterol were most common, although several participants reported other medical conditions such as asthma, gout, and complications that included kidney failure, limb amputation, vision impairment, and diminished sensitivity in the limbs. For these participants, the presence of these conditions slowed their progress.

Some participants were more disabled by the associated medical conditions than the stroke itself, as was seen in the case of Safiya, a 59-year-old housewife who was four years-post-stroke. 
She suffered from asthma and found it challenging to perform rehabilitation exercises as she was always breathless, "I can't exercise, [its] very difficult, I want to recover, but this asthma won't let me exercise. I become like a dog [panting]." Her example demonstrated how other medical conditions could slow or hamper individuals from pursuing recovery goals. The existence of comorbidities could undermine the benefits of rehabilitation. Some medications taken for the comorbidities such as anti-hypertensive drugs could cause headaches and fatigue which would, in turn, detract from rehabilitation activities. Similarly, conditions such as gout and arthritis could hinder rehabilitation efforts due to the exacerbated pain produced by physical exercises.

\section{External mediators}

\section{Support from family and friends}

Family support appeared to have a significant impact on participants' recovery. It provided them with emotional and financial aid, supporting them in fulfilling (or taking over) their previous roles, and assisting in therapeutic exercises. Yaqub, for example, described the support from his daughters and their husbands:

We have daughters; they look after us. Wherever I want to go, they take me. Even for prayers, before I regained the strength to ride the motorcycle, my sons-in-law would take me.

Because of the stroke survivors' disability, most families experienced changes in income level they were unprepared for. For the most part, participants had limited access to personal funds but were reliant on remittances from family members and government pensions to support them. Friends and religious organisations would also provide financial aid to the stroke survivor. Safiya regarded her spouse as her physical therapist. He assisted her in rehabilitation exercises at home, encouraging and motivating her:

When I had to learn to walk, he [husband] asked me to lean against the wall, asked me to do it every day. Then as time went by, I began to use the walker with four legs. He would wait behind, scared I might fall.

Safiya's spouse provided her with a safe and caring environment where she could manage her disability. Narratives from the participants demonstrated that the help and support from family were of enormous importance in the recovery path. Participants regularly made statements such as: "I couldn't have done it without them." The encouragement received helped the survivors achieve self-confidence and independence. Family boosted the survivor's will to recover.

Family, however, was not the only source of such socio-emotional support. Some participants mentioned the support they obtained from friends and neighbours.

People came to visit, gave advice, to recover quickly, prayers from friends. Friends came, just to chat, to give spirit. The neighbours helped out [too]. (Yaqub)

Yaqub had an extensive network of friends and lauded their efforts in helping him and his family through the recovery process. Similarly, Arjun, aged 77 (5 years-post-stroke), a still-active church member, was never short of friends to keep him company and attend to his needs:

I wake up around 7.30am ... if I need to get anything from the store I call my friend, he comes and takes me... when I go out, my friends help me.

These support networks were essential for participants' wellbeing through the provision of instrumental and emotional support, which helped encourage them to keep actively working on their recovery. Additionally, having maintained their network of friends helped to preserve salient aspects of the stroke survivor's identity, of who they were before the stroke such as churchgoers and sports enthusiasts. Amit, on the other hand, mentioned friends with bitterness in his tone when asked about his social network:

Few people came. Even when I had my leg amputated, my best friend didn't turn up. Sad! We used to work together... we would have tea and eat at the food stalls. It was a good time. All gone now.

Amit felt rejected and abandoned by friends. The rejection created bitterness within him accompanied by a lack of comprehension as to why he was rejected. An avid footballer before the stroke, he was also saddened by the loss of friends with whom he discussed and celebrated football with. The lack of social contact intensified the feelings of depression where life seemed bleak, full of despair and loneliness.

\section{Healthcare provider information}

Information provided by health professionals was mentioned as an essential aspect of recovery. Most participants were dissatisfied with the care they received at the hospital and the inadequacy of information about stroke. Yusuf, aged 59 (8 years-post-stroke), complained about the lack of information given to his spouse on how to take care of him after leaving the hospital, "They didn't give any information about caregiving. They just said there is no cure for stroke, that's all."

The limited information obtained from healthcare professionals at the hospitals created further anxiety and uncertainty for both participants and their caregivers on how to cope. Vague information on what was a stroke, its causes, prognosis and management left participants feeling neglected by the health system. However, some participants did admit that the limited information they did obtain proved to be valuable in their recovery:

The doctor said "don't get used to the walking stick." The doctor [also] said this type of sickness could recover; you have to take supplements, have to take care of our health... look after the diet, fewer fats, and sugar. (Sulaiman, aged 69, at 12 years-post-stroke)

While health professionals asked participants to adhere to medications and perform exercises to improve physical functioning, clear and adequate recovery intervention plans were not instituted. The participants were discharged home after a very brief hospital stay (average of 3 days) with limited information about their condition, limited rehabilitation and follow up plans. This brief hospital-stay supports other studies in Malaysia detailing short (5-7 days) in-hospital stays following stroke [32,33].

\section{Treatment management strategies}

Management strategies were described in two dimensions: management as prescribed by health professionals, and culturally-specific management, which comprised consultations with religious healers and the use of complementary and alternative medicine (CAM). These therapies comprised traditional Chinese, Malay and Islamic medicine that include massage, herbal medication, reflexology, homoeopathy and the use of special ceremonies and spells [34]. Most stroke survivors believed in a combination of both orthodox and CAM management, especially for their pre-existing medical conditions. Traditional therapies were seen to have an essential role in the restoration of muscle tone, improved blood circulation, and movement [34]. For most, treatment management 
of the condition was vital. They would take any medication or therapy recommended by anyone to recover, as Shuaib explained:

Hospital medication, traditional medicines advertised on TV, I bought all sorts of medicine. Even bird's nest, all. Whenever I hear about a particular medicine being effective, I bought it.

Shuaib's desire to recover meant he was ready to try anything and everything. He felt he needed to take control of his recovery by whatever means. It did not matter whether it was conventional treatment or CAM. The source of therapy was not important, all that mattered was the result. Ayub's desire to regain the capacity to care for his wife and young children led him to seek CAM treatments and endure the negative consequences of the treatment:

The massage, it's painful, but I endure it. People gave me all sorts of medications, the taste [is] sour, bitter [but] I take it. I have even tried drinking some liquid like that of a drain ... urgh the smell, but I just drank. I want to recover.

Like Ayub, the majority of participants used CAM. This occurred because there are pervasive acceptance and beliefs in the benefits of traditional medicine in Malaysian cultures [35,36]. Yusuf suffered from hypertension and, although he was compliant in taking his antihypertensive medications, he lauded CAM and credited part of his recovery to the massage he received:

Traditional massage every day for three months. No medication, just massage. They used water from white soil. After massaging with the white soil, I could walk, and my deformed mouth was back to normal.

This assertion of the benefits of CAM by participants highlighted the demand for the utilisation and or integration of CAM in the treatment management of stroke for survivors in Malaysia. The CAM masseurs and therapists were also a source of information and encouragement to the stroke survivors. They provided information about stroke, such as the possible causes, what exercises to perform, how to perform them and dietary advice. Umar, who had a history of hypertension and high blood cholesterol explained the dietary information provided by his masseur: "The masseur said: 'don't simply take medications, don't apply oil for a massage.' However, he said to take vegetables, soup, no fried food, mutton or beef." For these participants, CAM practitioners worked with the individual to help them heal. David's masseur, for example, not only provided him with massage but ensured that he performed physical exercises and moved about. He (masseur) explained:

Those that I massage, I teach them how to walk, squat and go up and down the stairs. If I only massage them, and they can't manage on their own, then it's useless .... what's the use of massage then? Have to teach them to manage themselves, else they have to rely on others.

It is an integrative approach that seeks to go beyond mere offering of treatment to provide a holistic approach to recovery.

The contextual factors affecting stroke recovery, although presented as internal and external mediators, are not mutually exclusive. The impairments brought about by the stroke limited the social interactions of the participants, thereby pulling them out of their familiar and supportive environment. This withdrawal and limitation in support networks, which is an external mediator, as described in the case of Amit, resulted in feelings of despair that affected the stroke survivors' optimism about recovery, an internal mediator. In comparison, information about stroke from healthcare providers, an external mediator, boosted morale, motivated and provided the survivors with resources to actively drive their recovery. Similarly, the use of religion as a coping mechanism, an internal mediator, governed some participants' stroke management approaches:

This sickness, it is as if there is something in our body... however, if we recite the Yaseen (a chapter in the Qur'an), it will stop. This is the Islamic medication. (Sulaiman, 69-years-old).

The use of and belief in the effectiveness of Islamic medicine for some of these survivors also reinforced their religious conviction, as they believed they were surrendering to the will of God. This external mediator of recovery aligned with their coping strategy of turning to religion.

\section{Discussion}

This study has emphasised the fact that although a stroke is a difficult and challenging event, survivors can adapt to the condition and resulting impairment. Several contextual factors can influence the recovery process. These factors, internal and external, exist interactively in the lived experiences of the survivors. This study explored the internal and external factors that mediated recovery from the perspective of stroke survivors. Recovery was a personal journey that involved motivation, commitment, hard work, and time, and was therefore individually defined and experienced [37]. Consistent with findings from prior research, our results suggest that the dynamics of the recovery process in stroke involves factors operating both within the individual and in interaction with the broader environment which should be considered [38]. The factors identified in this paper could be perceived as barriers or facilitators to recovery by different individuals. The factors may have different effects that are dependent on the individual and their subjective interpretation [39].

It is essential to recognise the limited health service environment that exists about stroke recovery in Malaysia: there are few rehabilitation centres in the country. All are privately run and located in urban centres, a considerable distance from our study site. The confluence of these factors meant that recovery predominately occurred outside of the biomedical health system - except comorbidity management - and instead relied upon the resources available to individuals and their families. The current paper examines the internal and external factors that shape the process of recovery within a context where infrastructure is minimal.

\section{Internal mediators}

Most of our participants expressed hope and optimism about recovery. Prior research has demonstrated that individuals with hope and optimism were likely to recover faster than those with lost hope [11,40,41]. Some of our participants alluded to motivation from other stroke survivors who have demonstrated resilience in dealing with the challenges of the stroke. Perceiving the success of others boosted their hope and optimism for recovery. Mostly, the participants showed self-efficacy, having confidence in their ability to manage the condition. This aspect corroborates work by prior authors who highlighted that self-efficacy was important for improving functional independence during rehabilitation $[42,43]$. High self-efficacy may help patients reclaim their ability to perform daily tasks, resulting in less dependence on others [44]. Self-efficacy, as underscored by Bandura (1977), provides resilience, pushing the individuals to remain strong regardless of minimal improvements as demonstrated by our participants.

The participants actively employed a variety of strategies to enable them to maintain their day-to-day activities in the face of impairment. Similar findings were reported by previous research 
where individuals dealing with chronic illness employed a variety of active coping strategies in response to their condition $[16,45,46]$. Religiosity, as a coping strategy, has been shown to protect stroke survivors from emotional distress, which may in turn aid recovery [47]. Other research also suggests some positive influence of faith on chronic disabling conditions [48-51].

Bodily states are also influential in supporting or impeding stroke recovery. Albrecht (1998) in his study on the paradox of disabilities showed that pain, fatigue and other medical conditions negatively affect the quality of life of individuals with disabilities. Our study showed that comorbid medical conditions adversely affected functional recovery in stroke. Similar findings have been reported in previous research where comorbidities had a negative correlation with functional outcomes and gains in individuals following a stroke [52]. Earlier studies have associated the presence of diabetes and heart disease amongst stroke survivors with poorer quality of life, affecting the recovery process $[53,54]$.

\section{External mediators}

Our results highlight that support and resources within the environment are essential for stroke survivors to engage in adaptive strategies with an aim to regain their lives. Health professional services and support, both orthodox and traditional as well as support from family members, friends, and the community, were necessary for the provision of emotional and instrumental supports that assisted the stroke survivors in their recovery process.

Support from family members was emphasised as significant in the recovery path. Pound and colleagues (1999), in their study of people living at home with stroke, highlight the family unit as a substantial resource in supporting stroke survivors. The support provided by the family became embedded in everyday life. The family assisted the stroke survivor in activities of daily living, such as feeding, toileting, and exercising. Similarly, the family acted as informal therapists by aiding with rehabilitation exercises, ensuring medications are adhered to and preventing further complications. The families in this study holistically provided support by not only supporting the stroke survivors in their personal needs but also by supporting the entire family unit. This is consistent with prior studies that found that family strength improved stroke outcomes $[55,56]$.

Our participants highlighted the need for better information about stroke and a clear recovery plan for health professionals. Our participants echoed other studies that suggest a general dissatisfaction with the limited information provided by health professionals $[14,15]$ and a lack of intervention plan post-discharge $[57,58]$. This dissatisfaction with services and a view that it hindered recovery has been reported in the Malaysian context $[18,59,60]$. Stroke survivors highlighted that limited information about stroke from health care providers hindered recovery and expressed a need for encouragement and feedback on progress. Resource constraints and the fragmented services within the Malaysian health services meant that specialised stroke services are often unavailable; leading to a shortage of skilled staff to provide adequate and timely information on stroke to survivors and their families as well a structured rehabilitation plan [23]. It was essential to the stroke survivors that they acquired information about the cause and nature of their stroke. They needed information and structured rehabilitation plans that would aid in their recovery. The literature emphasised that uncertainty and limited knowledge of the condition could reduce motivation for rehabilitation and hinder recovery $[61,62]$.
Participants credited the use of medication for helping them attain stable functioning of their pre-existing medical conditions and the use of traditional medical therapies for their stroke. It has long been part of the Malaysian culture to seek services of traditional healers when unwell. There is a deep-rooted belief in the benefits of traditional medicine for the treatment of chronic conditions and stroke in particular $[35,36,63]$. Most participants believe that stroke cannot be cured by orthodox medicine and rely heavily on the use of complementary and alternative medicine such as offered by traditional Chinese medicine; acupuncture, massage, herbs, and Islamic medicine. All the participants had tried one or a combination of the traditional therapies. Most reported improvements in their condition and believed it had aided significantly in their recovery. A few, however, claim no benefit came from the treatments. Studies in CAM for stroke recovery have highlighted the benefits of acupuncture, massage, exercises and herbal or vitamin supplements [64-69]. These studies argue that CAM aids with symptom relief increased mobility and improved mood in stroke survivors. The use of non-biomedical practitioners in stroke management in South-East Asia has been documented in a study conducted in Indonesia [70]. The study emphasised the acceptance and reliance of CAM in the management of stroke and calls for further exploration of its possible incorporation within international stroke management.

CAM practitioners undergo higher education programs that are accredited by the Malaysian Qualifications Agency (MQA) [71]. However, some practitioners are not certified by professional bodies and claim to inherit their skills through mystical powers or past traditional practitioners [36,72]. In 2007, the Malaysian Ministry of Health, recognising the importance and need for CAM, integrated CAM units within three hospitals. These units offer acupuncture, herbal medicine for patients with cancer, and the traditional Malay massage to help in the rehabilitation of post-stroke patients [36]. As of 2015, nine public hospitals in Malaysia integrated CAM units within their structure [72].

\section{Implications for practice}

The identification of factors that facilitate the recovery process provides a background with which health care providers can utilise to improve their understanding of the stroke experience, the strengths, and weaknesses of their patients. The practitioner's role in this is to support the stroke survivor by eliciting individual attributes which characterise their recovery and prepares the individual for successful self-management. Peer-provided services or support groups where some stroke survivors serve as role models for other survivors may help to foster hope for those struggling to accept their condition and recovery process. Practitioners should further promote hope and manage the expectations of their patients, conveying the message that a pre-stroke life might not be achievable, but it is possible to live a fulfilling and purposeful life [73].

Furthermore, boosting confidence in task performance may aid in averting deterioration and improve recovery. Individuals who are self-efficacious, feel confident in their ability to manage activities of daily living and thus will continue to perform necessary activities [43]. The progress made by individuals, albeit minimal may be vital in reinforcing an optimistic view that further improvements may occur.

Religion plays a central role for Malaysians, due to the spiritual, psychological and physiological comfort it provides. The results of the study show that improved healthcare provider's understanding and recognition of the importance of religious coping in 
stroke survivors may aid in their recovery. The literature highlights that some health care professionals may be reluctant to incorporate religion into rehabilitation as it is not a scientifically validated method of coping with disability [74-76]. However, given the context of this study, incorporation of religion into rehabilitation could support and maintain hope in recovery for the survivors and aid acceptance. This aspect, although not generalizable globally, may be an important point of consideration for individuals in locales where religion plays a significant role in the day-to-day lives of the population. Strengthening stroke survivors' religious beliefs may aid them in coping with their disability by providing new meaning to their lives and lessening their emotional distress $[74,77]$. Furthermore, as the Islamic practice of the salah involves bodily movements, some studies have suggested that the salah could help with cerebral blood flow and postural reflexes [78,79].

As most strokes occur in the context of other medical conditions [80], the recognition and management of comorbidities are essential for the achievement of successful recovery. The burden of comorbidities may slow rehabilitation progress. Health professionals, therefore, need to provide a holistic management approach where the individual is assessed and managed not just as a stroke survivor but as an individual considering other medical conditions he may have. Complementary and alternative medicine therapy is a universal healthcare choice adopted by most individuals with stroke in Malaysia. In a Malaysian context, a more robust collaboration of healthcare professionals with traditional medicine therapists may prove beneficial for the rehabilitation of stroke survivors. The incorporation of CAM into conventional clinical practice may provide stroke survivors with psychological relief, improved emotional regulation, increased mobility, improvements in activity and participation in activities of daily living. Though it remains unclear how CAM practitioners manage stroke within a biomedical paradigm of care [70], a partnership with healthcare professionals and incorporation of CAM regimens into conventional clinical practice may prove beneficial for the acceptance and rehabilitation of stroke survivors. This assertion calls for international models of care for stroke, to examine the best practices of care within individual contexts [70].

It is essential to balance rehabilitation with adequate information and emotional support throughout the inpatient rehabilitation phase. The provision of information by health professionals, which should go beyond didactic information to include a well laid out rehabilitation plan for the stroke survivors and their caregivers, is imperative.

\section{Strengths and limitations}

This study was conducted as part of a broader research that investigated the experience of recovery from stroke, as such, the amount of data on the factors that mediated recovery was limited. The findings are from a small sample of stroke survivors whose experience may not be reflective of the broader populace. However, the sample recruited fairly represented the ethnic and religious mix distribution of Malaysia. As this is a qualitative study, data interpretation could be subjective. However, the authors attempted to lessen bias using robust data collection and analysis techniques. While the study reflected more men suffered from stroke, it is beyond the scope of this paper to speculate about the reasons for this, but it may be reflective of differential survival rates following stroke and warrants further investigation. This study contributes to the literature on recovery by offering insights into the contextual factors that guide recovery from stroke in
Malaysia. The study, can, therefore, be considered a valuable contribution to the field of stroke care at the community level.

\section{Acknowledgements}

The study was funded through the Australian Research Council (Discovery Project Scheme, project number DP140101995). Data collection was undertaken at the Monash SEACO HDSS technology research platform. The authors would like to express their appreciation to the SEACO Field Team and members of the SEACO Scientific Advisory Group from the Malaysian Ministry of Health. SEACO is funded by the Monash University Malaysia Campus; the Office of the Vice Provost Research, Monash University Australia; the office of the Deputy Dean Research, Faculty of Medicine, Nursing and Health Sciences, Monash University Australia; The Faculty of Arts, Monash University Australia, and the Jeffrey Cheah School of Medicine and Health Sciences, Monash University Malaysia. SEACO is an associate member of the INDEPTH Network.

\section{Disclosure statement}

The authors declare no conflict of interests.

\section{Funding}

This work was supported by Australian Research Council Discovery Project Scheme [DP140101995].

\section{ORCID}

Fatima Fanna Mairami iD http://orcid.org/0000-0003-2429-5248

Narelle Warren (iD http://orcid.org/0000-0003-2623-4078

Pascale A. Allotey (D) http://orcid.org/0000-0002-6942-5774

Daniel D. Reidpath (D) http://orcid.org/0000-0002-8796-0420

\section{References}

[1] Billinger SA, Arena R, Bernhardt J, et al. Physical activity and exercise recommendations for stroke survivors: a statement for healthcare professionals from the American Heart Association/American Stroke Association. Stroke. 2014;45: 2532-2553.

[2] Anderson CS, Linto J, Stewart-Wynne EG. A populationbased assessment of the impact and burden of caregiving for long-term stroke survivors. Stroke. 1995;26:843-849.

[3] Raju RS, Sarma PS, Pandian JD. Psychosocial problems, quality of life, and functional independence among Indian stroke survivors. Stroke. 2010;41:2932-2937.

[4] Tyedin K, Cumming TB, Bernhardt J. Quality of life: an important outcome measure in a trial of very early mobilisation after stroke. Disabil Rehabil. 2010;32:875-884.

[5] Carod-Artal J, Egido JA, González JL, et al. Quality of life among stroke survivors evaluated 1 year after stroke: experience of a stroke unit. Stroke. 2000;31:2995-3000.

[6] Brookfield K, Mead G. Physical environments and community reintegration post stroke: qualitative insights from stroke clubs. Disabil Soc. 2016;31:1013-1029.

[7] Burton CR. Living with stroke: a phenomenological study. J Adv Nurs. 2000;32:301-309. 
[8] Pawlson L. Chronic illness: implications of a new paradigm for health care. Jt Comm J Qual Improv. 1994;20:33-39.

[9] Langhorne P, Bernhardt J, Kwakkel G. Stroke rehabilitation. Lancet. 2011;377:1693-1702.

[10] Dowswell G, Lawler J, Dowswell T, et al. Investigating recovery from stroke: a qualitative study. J Clin Nurs. 2000; 9:507-515.

[11] Jones F, Mandy A, Partridge C. Reasons for recovery after stroke: A perspective based on personal experience. Disabil Rehabil. 2008;30:507-516.

[12] Ellis-Hill C, Robison J, Wiles R, et al. On Behalf of the Stroke Association Rehabilitation Research Centre T. Going home to get on with life: Patients and carers experiences of being discharged from hospital following a stroke. Disabil Rehabil. 2009;31:61-72.

[13] Martinsen R, Kirkevold $M$, Sveen U. Young and midlife stroke survivors' experiences with the health services and long-term follow-up needs. J Neurosci Nurs. 2015;47:27-35.

[14] Eames S, Hoffmann T, Worrall L, et al. Stroke patients' and carers' perception of barriers to accessing stroke information. Top Stroke Rehabil. 2010;17:69-78.

[15] Ing MM, Linton KF, Vento MA, et al. Investigation of Stroke Needs (INVISION) Study: stroke awareness and education. Hawaii J Med Public Health. 2015;74:141.

[16] Pound P, Gompertz P, Ebrahim S. Social and practical strategies described by people living at home with stroke. Health Soc Care Community. 1999;7:120-128.

[17] Lo Buono V, Corallo F, Bramanti P, et al. Coping strategies and health-related quality of life after stroke. J Health Psychol. 2017;22:16-28.

[18] Mohamed CR. The educational needs of home-based stroke patients and family caregivers in Malaysia. Doctoral Theses, University of Wellington, New Zealand. 2010.

[19] Abdul Aziz AF, Aziz NA, Sulong S, et al. The post discharge stroke care services in Malaysia: a pilot analysis of selfreported practices of family medicine specialists at public health centres. BMC Public Health 2012;12:A1-AA.

[20] Wyller TB, Sveen U, Sødring KM, et al. Subjective well-being one year after stroke. Clin Rehabil. 1997;11:139-145.

[21] Peters DJ. Disablement observed, addressed, and experienced: integrating subjective experience into disablement models. Disabil Rehabil. 1996;18:593-603.

[22] Allotey P, Reidpath DD, Devarajan N, et al. Cohorts and community: a case study of community engagement in the establishment of a health and demographic surveillance site in Malaysia. Glob Health Action. 2014;7(1):23176.

[23] Kooi CW, Peng HC, Aziz ZA, et al. A review of stroke research in Malaysia from 2000-2014. Med J Malaysia 2016; 71:58-69.

[24] Madden R. Being ethnographic: a guide to the theory and practice of ethnography. London: SAGE Publications Limited; 2017.

[25] Braun V, Clarke V. Using thematic analysis in psychology. Qual Res Psychol. 2006;3:77-101.

[26] Murphy J, Oliver T. The use of Talking Mats to support people with dementia and their carers to make decisions together. Health Soc Care Community. 2013;21:171-180.

[27] Murphy J, Tester S, Hubbard G, et al. Enabling frail older people with a communication difficulty to express their views: the use of Talking Mats ${ }^{\mathrm{TM}}$ as an interview tool. Health Soc Care Community. 2005;13:95-107.

[28] Bandura A. Self-efficacy: toward a unifying theory of behavioral change. Psychol Rev. 1977;84:191.
[29] Carver CS, Scheier MF, Weintraub JK. Assessing coping strategies: a theoretically based approach. J Pers Soc Psychol. 1989;56:267.

[30] Carin-Levy G, Kendall M, Young A, et al. The psychosocial effects of exercise and relaxation classes for persons surviving a stroke. Can J Occup Ther. 2009;76:73-80.

[31] Kneebone I, Walker-Samuel N, Swanston J, et al. Relaxation training after stroke: potential to reduce anxiety. Disabil Rehabil. 2014;36:771-774.

[32] Nordin NAM, Aziz NA, Alkaff SE, et al. Rehabilitation for patients after stroke in a tertiary hospital: is it early and intensive enough? Int J Ther Rehabil. 2012;19:603-611.

[33] Hamidon BB, Raymond A. Risk factors and complications of acute ischaemic stroke patients at Hospital Universiti Kebangsaan Malaysia (HUKM). Med J Malaysia. 2003;58: 499-505.

[34] Kadir AA, Hamid AHA, Mohammad M. Pattern of complementary and alternative medicine use among Malaysian stroke survivors: A hospital-based prospective study. J Tradit Complement Med. 2015;5:157-160.

[35] Aziz Z, Tey N. Herbal medicines: prevalence and predictors of use among Malaysian adults. Complement Ther Med. 2009;17:44-50.

[36] Anuar HM, Fadzil F, Ahmad N, et al. Urut Melayu for poststroke patients: a qualitative study. J Altern Complement Med. 2012;18:61-64.

[37] Slade $M$, Amering $M$, Oades L. Recovery: an international perspective. Epidemiol Psichiatr Soc. 2008;17:128-137.

[38] Albrecht GL, Devlieger PJ. The disability paradox: high quality of life against all odds. Soc Sci Med. 1999;48: 977-988.

[39] Algurén B, Lundgren-Nilsson Å, Sunnerhagen KS. Facilitators and barriers of stroke survivors in the early post-stroke phase. Disabil Rehabil. 2009;31:1584-1591.

[40] Räikkönen K, Matthews KA, Flory JD, et al. Effects of optimism, pessimism, and trait anxiety on ambulatory blood pressure and mood during everyday life. J Pers Soc Psychol. 1999;76:104

[41] Cross A, Schneider M. A Preliminary Qualitative Analysis of the Impact of Hope on Stroke Recovery in Women. Top Stroke Rehabil. 2010;17:484-495.

[42] Cott C. Client-centred rehabilitation: client perspectives. Disabil Rehabil. 2004;26:1411-1422.

[43] Robinson-Smith G, Pizzi ER. Maximizing stroke recovery using patient self-care self-efficacy. Rehabil Nurs. 2003;28: 48-51.

[44] Hellstrom K, Lindmark B, Wahlberg B, et al. Self-efficacy in relation to impairments and activities of daily living disability in elderly patients with stroke: a prospective investigation. J Rehabil Med. 2003;35:202-207.

[45] Bury M. Chronic illness as biographical disruption. Sociol Health IIIn. 1982;4:167-182.

[46] Smout S, Koudstaal P, Ribbers G, et al. Struck by stroke: a pilot study exploring quality of life and coping patterns in younger patients and spouses. Int J Rehabil Res. 2001;24: 261-268.

[47] Giaquinto S, Spiridigliozzi C, Caracciolo B. Can faith protect from emotional distress after stroke? Stroke. 2007;38: 993-997.

[48] Unantenne N, Warren N, Canaway R, et al. The strength to cope: spirituality and faith in chronic disease. J Relig Health. 2013;52:1147-1161. 
[49] Koenig HG. Religion, spirituality, and health: the research and clinical implications. ISRN Psychiatry. 2012;2012:1.

[50] Harris ST, Koenig HG. An 81-year-old woman with chronic illnesses and a strong faith. J Complement Integr Med. 2016;13:83-89.

[51] Koenig $\mathrm{H}$, McCullough M, Larson D. Handbook of religion and health. New York: Oxford University Press; 2001.

[52] Karatepe AG, Gunaydin R, Kaya T, et al. Comorbidity in patients after stroke: impact on functional outcome. J Rehabil Med. 2008;40:831-835.

[53] Mackenzie A, Chang A. Predictors of quality of life following stroke. Disabil Rehabil. 2002;24:259-265.

[54] Lai S-M, Studenski S, Duncan PW, et al. Persisting consequences of stroke measured by the Stroke Impact Scale. Stroke. 2002;33:1840-1844.

[55] Niyomthai N, Tonmukayakul O, Wonghongkul T, et al. Family strength in caring for a stroke survivor at home. Pac Rim Int J Nurs Res. 2010;14:17-31.

[56] Cecil R, Thompson K, Parahoo K, et al. Towards an understanding of the lives of families affected by stroke: a qualitative study of home carers. J Adv Nurs. 2013;69: 1761-1770.

[57] Smith LN, Lawrence M, Kerr SM, et al. Informal carers' experience of caring for stroke survivors. J Adv Nurs. 2004; 46:235-244.

[58] Tholin H, Forsberg A. Satisfaction with care and rehabilitation among people with stroke, from hospital to community care. Scand J Caring Sci. 2014;28:822-829.

[59] Aziz AFA, Nordin NAM, Aziz NA, et al. Care for post-stroke patients at Malaysian public health centres: self-reported practices of family medicine specialists. BMC Fam Pract. 2014;15:40.

[60] Eng XW, Brauer SG, Kuys SS, et al. Factors affecting the ability of the stroke survivor to drive their own recovery outside of therapy during inpatient stroke rehabilitation. Stroke Res Treat. 2014;2014:1.

[61] Laskiwski S, Morse JM. The patient with spinal cord injury: the modification of hope and expressions of despair. Can J Rehabil. 1993;6(3):143-153.

[62] Barker R, Brauer S. Upper limb recovery after stroke: the stroke survivors' perspective. Disabil Rehabil. 2005;27: 1213-1223.

[63] Siti Z, Tahir A, Farah Al, et al. Use of traditional and complementary medicine in Malaysia: a baseline study. Complement Ther Med. 2009;17:292-299.

[64] $\mathrm{Xu} \mathrm{H}$. A summary of clinical treatment for 58 cases of hemiplegia with electro-acupuncture and massage. J Tradit Chin Med. 2000;20:48-50.

[65] Chen D. Comparative study of chuanxiong and dextran 40 in the treatment of acute cerebral infarction. Zhongguo Zhong Xi Yi Jie He Za Zhi. 1992;12:71-73. 67.
[66] Han S-Y, Hong Z-Y, Xie Y-H, et al. Therapeutic effect of Chinese herbal medicines for post stroke recovery: a traditional and network meta-analysis. Medicine. 2017;96(49): e8830.

[67] Van Puymbroeck M, Allsop J, Miller KK, et al. ICF-based improvements in body structures and function, and activity and participation in chronic stroke following a yoga-based intervention. Am J Recreat Ther. 2017;13:23-33.

[68] Winser SJ, Tsang WW, Krishnamurthy K, et al. Does Tai Chi improve balance and reduce falls incidence in neurological disorders? A systematic review and meta-analysis. Clin Rehabil. 2018;32(9):1157-1168.

[69] Tseng S-P, Hsu Y-C, Chiu C-J, et al. A population-based cohort study on the ability of acupuncture to reduce poststroke depression. Medicines (Basel). 2017;4:16.

[70] Norris M, Allotey P, Barrett G. Nonbiomedical stroke practitioners in Aceh. Int J Stroke. 2011;6:152-154.

[71] Ministry of Health Malaysia Opotacmd. Published [cited 2018 Sept 14]. Available from: http://tcm.moh.gov.my/en/ index.php/education/higher-education

[72] Ikram RRR, Ghani MKA. An overview of traditional Malay medicine in the Malaysian healthcare system. J Appl Sci. 2015;15:723.

[73] Salyers MP, Macy VR. Recovery-oriented evidence-based practices: a commentary. Community Ment Health J. 2005; 41:101-103.

[74] Johnstone B, Glass BA, Oliver RE. Religion and disability: clinical, research and training considerations for rehabilitation professionals. Disabil Rehabil. 2007;29:1153-1163.

[75] Lawrence RJ. The witches' brew of spirituality and medicine. Ann Behav Med. 2002;24:74-76.

[76] Sloan RP, Bagiella E, VandeCreek $L$, et al. Should physicians prescribe religious activities?. N Engl J Med. 2000;342: 1913-1916.

[77] Cigrang JA, Hryshko-Mullen A, Peterson AL. Spontaneous reports of religious coping by patients with chronic physical illness. J Clin Psychol Med Settings. 2003;10:133-137.

[78] Reza MF, Urakami Y, Mano Y. Evaluation of a new physical exercise taken from salat (prayer) as a short-duration and frequent physical activity in the rehabilitation of geriatric and disabled patients. Ann Saudi Med. 2002;22:177-180.

[79] Safee MKM, Abas WABW, Ibrahim $F$, et al. Electromyographic activity of the lower limb muscles during salat and specific exercises. J Phys Ther Sci. 2012;24: 549-552.

[80] Nelson ML, McKellar KA, Yi J, et al. Stroke rehabilitation evidence and comorbidity: a systematic scoping review of randomized controlled trials. Top Stroke Rehabil. 2017;24: 374-380. 